\title{
Ezrin overexpression predicts the poor prognosis of gastric adenocarcinoma
}

Jingchun Jin ${ }^{1,4 \dagger}$, Tiefeng Jin ${ }^{1,2 \dagger}$, Meiling Quan ${ }^{1,2}$, Yingshi Piao ${ }^{2,3}$ and Zhenhua Lin ${ }^{1,2^{*}}$

\begin{abstract}
Background: Ezrin is a cytoskeletal protein that is involved in tumor growth and invasion. It has been suggested that Ezrin expression plays an important role in tumor metastasis. This study is aimed to investigate the clinicopathological significance of Ezrin overexpression in gastric adenocarcinomas.

Methods: Ezrin protein expression was examined by immunohistochemistry in 26 normal gastric mucosa, 32 dysplasia, and 277 gastric adenocarcinomas. The relationship between Ezrin expression and the clinicopathological features of gastric cancers was analyzed. In addition, a gastric cancer cell line, MKN-1, was also used for immunofluorescence staining to evaluate the distribution of Ezrin protein.

Results: Ezrin protein located in the cytoplasm and/or membrane in the migrating gastric cancer cells, and it mainly concentrated at the protrusion site; however, only cytoplasmic distribution was observed in the non-migrating cancer cells by immunofluorescence staining. The positive rate of Ezrin protein expression was significantly higher in gastric adenocarcinoma and dysplasia compared with that in the normal gastric mucosa. Moreover, expression frequency of Ezrin protein increased significantly in lymph node metastasis and late clinical stages. Consistently, strong expression of Ezrin was significantly correlated with poor prognosis of gastric cancer.

Conclusion: The detection of Ezrin expression can be used as the marker for early diagnosis and prognosis of gastric adenocarcinoma.

Virtual Slides: The virtual slide(s) for this article can be found here: http://www.diagnosticpathology.diagnomx.eu/ vs/2303598677653946
\end{abstract}

Keywords: Gastric adenocarcinoma, Ezrin, Tissue microarray

\section{Introduction}

Gastric cancer is one of the most fatal malignant tumors worldwide. The poor prognosis is associated with extensive local invasion and/or regional lymph node metastasis [1]. Local recurrence remains the cause of cancer-related deaths after resection in a substantial proportion of patients with gastric cancer. Therefore, establishing reliable criteria to predict recurrence and to identify the tumors is of great interest not only for understanding the molecular and cellular processes

\footnotetext{
* Correspondence: zhlin720@ybu.edu.cn

${ }^{\dagger}$ Equal contributors

'Department of Pathology, Yanbian University Medical College, Yanji-City 133002, Jilin-Prov., P.R. China

${ }^{2}$ Cancer Research Center, Yanbian University, Yanji-City 133002, Jilin-Prov., P.R. China

Full list of author information is available at the end of the article
}

involved in tomorigenesis, but also for searching the possible new therapeutic molecular targets [2].

Tumor metastasis starts with breakdown of epithelial integrity, followed by malignant cells invading into the surrounding stroma and lymphovascular space, by which tumor cells travel to distant target organs [3,4]. Cell adhesion molecules and actin cytoskeleton play a crucial role in tumor metastasis $[5,6]$. The primary mechanism for most types of cell migration is the actin cytoskeleton remodeling [7]. The cytoskeletal protein Ezrin is a member of the Ezrin-Radixin-Moesin (ERM) family which is linked to aggressive tumor behavior by involving all stages of tumor metastasis $[7,8]$ including cell adhesion, survival, motility, and signal transduction [9-11].

Recent publications showed that Ezrin is strongly expressed in a variety of invasive cancers, including osteosarcoma, melanoma, soft tissue sarcoma, pancreatic

\section{Biomed Central}

(C) 2012 Jin et al.; licensee BioMed Central Ltd. This is an Open Access article distributed under the terms of the Creative Commons Attribution License (http://creativecommons.org/licenses/by/2.0), which permits unrestricted use, distribution, and reproduction in any medium, provided the original work is properly cited. 
carcinoma, hepatocellular carcinoma and gastric and breast cancers [2,11-17]. There is accumulating evidence suggesting that Ezrin is a metastatic determinant and a key component in tumor metastasis, however, its exact role in gastric cancer is still unknown. Bal et al. [18] reported that there was a negative correlation between Ezrin and lymph node metastasis, lymphovascular space invasion, and perineural invasion in all gastric carcinomas, but was not statistically significant $(\mathrm{P}>0.05)$, while no association with depth of invasion, tumor location, tumor size and distant metastasis $(P>0.05)$. However, Zhao et al. [19] and Li et al. [20] reported that positive expression of Ezrin correlated with age, tumor size, location, differentiation stage, depth of invasion, vessel invasion, lymph node and distant metastasis, and TNM stage $(\mathrm{P}<0.05)$. In present study, we therefore aimed to investigate the Ezrin protein expression in human gastric adenocarcinoma and its precancerous lesions, and to explore the exactly relation of Ezrin expression to the clinical outcomes and the histological parameters of gastric cancers.

\section{Materials and methods Clinical samples}

Total 335 tissue samples, including 277 cases of gastric adenocarcinomas, 32 cases of dysplasia and 26 of normal gastric tissues, were collected from Shanghai Outdo Biotech Co. Ltd. (Outdo Biotech) and Department of Pathology, The Third Affiliated People's Hospital of Shanghai Jiaotong University. All tissues were routinely fixed in $10 \%$ buffered formalin and embedded in paraffin blocks. The study protocol was approved by the institutional review board of Yanbian University Medical College.

The pathological parameters, including age, gender, histological types, differentiation, the presence of nodal metastasis, clinical stage and disease free survival, were carefully reviewed in all of 277 gastric adenocarcinomas. The patients' age ranged from 36 to $78 \mathrm{yr}$ with a mean age of $51.7 \mathrm{yr}$. The male to female ratio was 164:113. Of the 277 gastric adenocarcinomas encompassed 39 cases of TNM stage 0,98 cases of TNM stage I (TNM stage IA $=47$, TNM stage IB $=51$ ), 75 cases of TNM stage II, 59 cases of TNM stage III, and 6 cases of TNM stage IV. In which, 85 cases were well differentiated adenocarcinoma, 103 cases as moderately differentiated, 59 cases as poorly differentiated, 5 cases as undifferentiated, 9 cases as signet ring cell carcinomas, and 16 cases as mucinous adenocarcinoma. For the Lauren types, 117 cases were intestinal type, 139 cases as diffuse type, and 21 cases as mixed types. TNM staging was assessed according to the staging system established by the American Joint Committee on Cancer (AJCC) [21]. Of the 277 gastric adenocarcinomas, 151 cases were lymph node (LN) metastasis negative, and 126 cases were LN meatastasis positive. In total 277 of gastric adenocarcinomas, $54.9 \%$ $(152 / 277)$ of cases were more than three years of disease free survival. Additionally, the normal gastric mucosa tissues were obtained from the resection margins of radical specimen of gastric cancer.

\section{Immunofluorescence staining for Ezrin protein in cancer cells in vitro}

Gastric cancer cell line MKN-1 was grown on coverslips to $100 \%$ confluence, and then continued to culture with FBS free medium for 24 hours after being scratched by a new $200 \mu$ pipette tip for searching the migrating cells. The cells were then fixed with $4 \%$ paraformaldehyde for 10 minutes and permeabilized with $0.5 \%$ TritonX-100 for 10 minutes after 24 hours. Blocking was performed with 3\% Albumin Bovine V (A8020, Solarbio, Beijing, China) for one hour at the room temperature. After washing with PBS, cells were incubated with antibody against Ezrin (1:100, \#3145, Cell Signaling Technology, Boston, USA) for two hours, and followed the incubation by Alexa Fluor ${ }^{\circledR} 488$ goat anti-rabbit $\operatorname{IgG}(\mathrm{H}+\mathrm{C})$ (A11008, Invitrogen, USA) for one hour at room temperature. After washing with PBS, the cells were counterstained with 49-6-diamidino-2-phenylindole (DAPI) (C1006, Beyotime, Shanghai, China), and the coverslips were mounted with Antifade Mounting Medium (P0126, Beyotime, Shanghai, China). Finally, the immunofluorescence signals were visualized and recorded by Leica SP5II confocal microscope.

\section{Immunohistochemistry for Ezrin protein in paraffin-embedded tissues}

Dako LSAB kit (Dako, Glostrup, Denmark) was used for immunohistochemistry. And the serial $4 \mu \mathrm{m}$-thick tissue sections were prepared on silane-coated slides (Sigma, St Louis, MO, USA), and deparaffinized, rehydrated and incubated with $3 \% \mathrm{H}_{2} \mathrm{O}_{2}$ in methanol for 5 minutes at room temperature to eliminate endogenous peroxidase activity. The antigen was retrieved at $95^{\circ} \mathrm{C}$ for 20 minutes by placing the slides in $10 \mathrm{mM}$ sodium citrate buffer ( $\mathrm{pH}$ 6.0). The slides were then incubated with primary antibody Ezrin (1:50, \#3145, Cell Signaling Technology, Boston, USA) at $4^{\circ} \mathrm{C}$ for overnight. After incubation at room temperature for 30 minutes with biotinylated secondary antibody, the slides were incubated with streptavidin-peroxidase complex at room temperature for 30 minutes. Immunostaining was developed by using chromogen, 3,3'-diaminobenzidine, and counterstained with Mayer's hematoxylin. Rabbit IgG isotope used as the control and the result is negative. Also, the positive tissue sections were processed omitting the primary antibody as negative controls. 


\section{Interpretation of immunohistochemical staining}

All slides were scored independently by two investigators (Lin $\mathrm{Z}$ and Piao $\mathrm{Y}$ ) being blinded to all clinical data. The interpretation criteria were described previously by Elzagheid A et al. [22]. Briefly, lymphocytes served as a reference for strong immunoreactivity (Figure 1), and the immunoreactivity was graded into four categories: $+++($ score 3$)=$ similar to the lymphocyte staining; ++ (score 2$)=$ less than $+++;+($ score 1$)=$ distinguishable from the background staining; and - (score 0$)=$ completely negative. Only the cytoplasmic and membranous expression was considered as positive staining and the strong positive means ' ++ ' and ' +++ ' positive cells.

\section{Statistical analysis}

Statistical analysis was performed using the Chi-square $\left(x^{2}\right.$-test) test and Mean-Whitney test of SPSS software program for windows, version 17.0 (SPSS, Chicago, USA). P-value less than 0.05 considered significant.

\section{Results}

The characteristics of Ezrin protein localization and distribution

To observe the localization of Ezrin protein in migrating and non-migrating cancer cells, the cultured MKN-1 gastric cancer cells were scratched by a new $200 \mu \mathrm{l}$ pipette tip (Figure 1), and then the immunofluorescence staining for Ezrin protein was done. It was found that Ezrin protein located at the cytoplasm and/or membrane in the migrating MKN-1 cells, and mainly concentrated at the protrusion site; however, only cytoplasmic

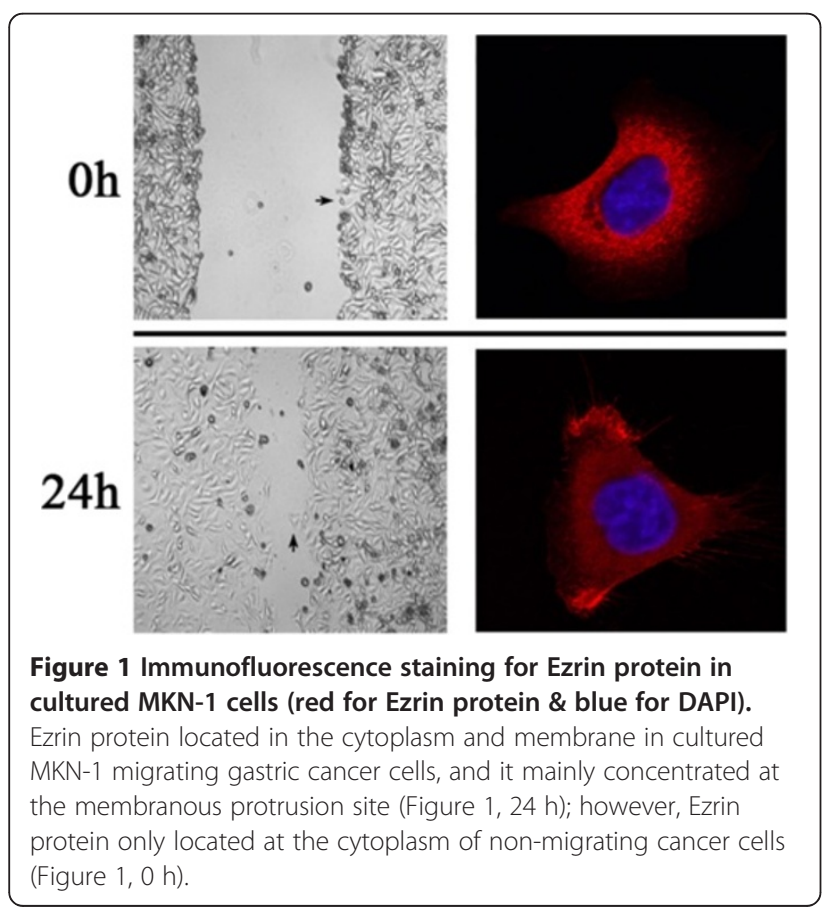

distribution was observed in the non-migrating MKN-1 cells by immunofluorescence staining (Figure 1). For the tissue sections, diffusely and strongly positive signals for Ezrin protein was detected in the cytoplasm of gastric cancer cells, however negative or scattered positive cells, mainly basal reserve cells, was observed in the normal gastric epithelia by immunohistochemistry. Interestingly, single scattered cancer cells or invasive cancer loci at the stroma frequently showed strongly and most intense immunoreactivity for Ezrin protein (Figure 2).

\section{Correlation between Ezrin protein overexpression and clinical parameters of gastric cancers}

Ezrin protein showed higher positivity in gastric adenocarcinoma (score 1, 79.8\%, 221/277; score 2, 60.6\%, 168/ 277 ) compared with the adjacent normal gastric mucosa (score 1, 19.2\%, 5/26; score 2, 0, 0/26). Also, Ezrin protein was strongly positive in gastric dysplasia (score 1, $65.6 \%, 21 / 32$; score $2,37.5 \%, 12 / 32$ ) on immunohistochemistry, which was also significantly higher than normal gastric tissues (score 1, 19.2\%, 5/26; score 2, 0\%, $0 / 26)$. Similarly, Lauren intestinal $(65.8 \%, 77 / 117)$ and diffuse $(61.2 \%, 85 / 139)$ types of gastric cancer also determined strongly expression rate of Ezrin protein compared to the mixed type $(28.6 \%, 6 / 21)$ cases $(\mathrm{P}<0.05)$. (Figures $2 \& 3$, Tables $1 \& 2$ ).

Additionally, Ezrin protein overexpression was significantly correlated with the lymph node metastasis of gastric adenocarcinoma. The strongly positive rates of Ezrin were $35.1 \%(53 / 151)$ and $91.3 \%(115 / 126)$ in nonmetastatic and metastasic carcinoma of stomach, respectively $(\mathrm{P}<0.01)$. For the TNM clinical stages, Ezrin positive rate was only $35.8 \%(49 / 137)$ in early clinical stage $(35.9 \%$ in Stage 0, $25.5 \%$ in stage IA and $45.1 \%$ in stage IB) of gastric cancer, however significantly higher in late stage cases $(85.0 \%, 119 / 140)(78.7 \%$ in Stage II, $91.5 \%$ in stage III, and $100 \%$ in stage IV), and the difference was statistically significant $(\mathrm{P}<0.05)$. Also, the strongly positive rate of Ezrin protein expression was significantly higher in $<3$ years disease free survival cases $(92.0 \%, 115 / 125)$ than it in $\geq 3$ years disease free survival cases $(34.9 \%, 53 / 152)(\mathrm{P}<0.01)$. However, Ezrin protein expression level was not correlated with the patient age, gender, histological type status of gastric adenocarcinoma $(\mathrm{P}>0.05)$ (Figure 3, Table 2).

\section{Discussion}

Gastric cancer is the one of most common malignant tumor worldwide. Despite effective control of the primary tumor and both neoadjuvant and adjuvant chemotherapy, the development of metastases is still the common cause of death in gastric cancer patients [23,24]. The development of new and effective treatments based on the well understanding of metastasis biology is needed. 


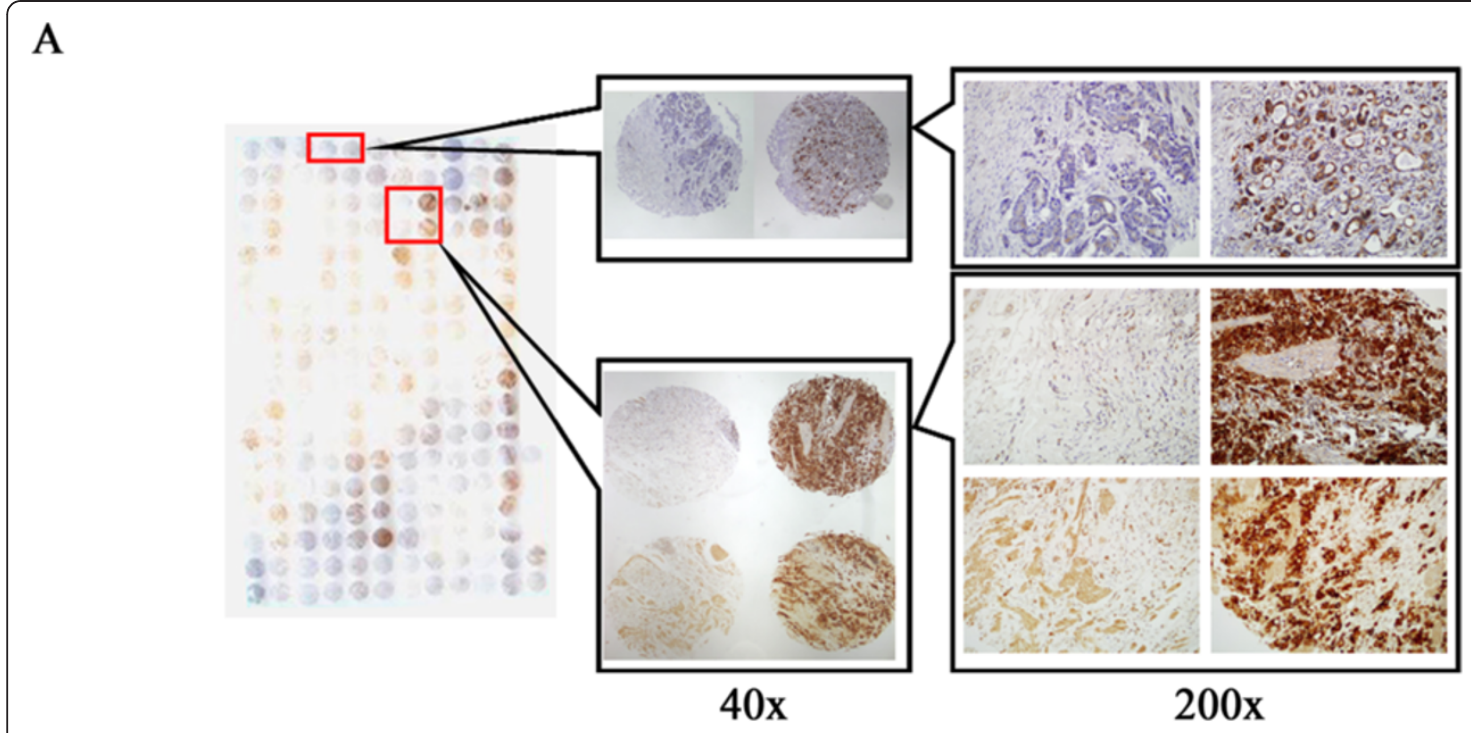

B
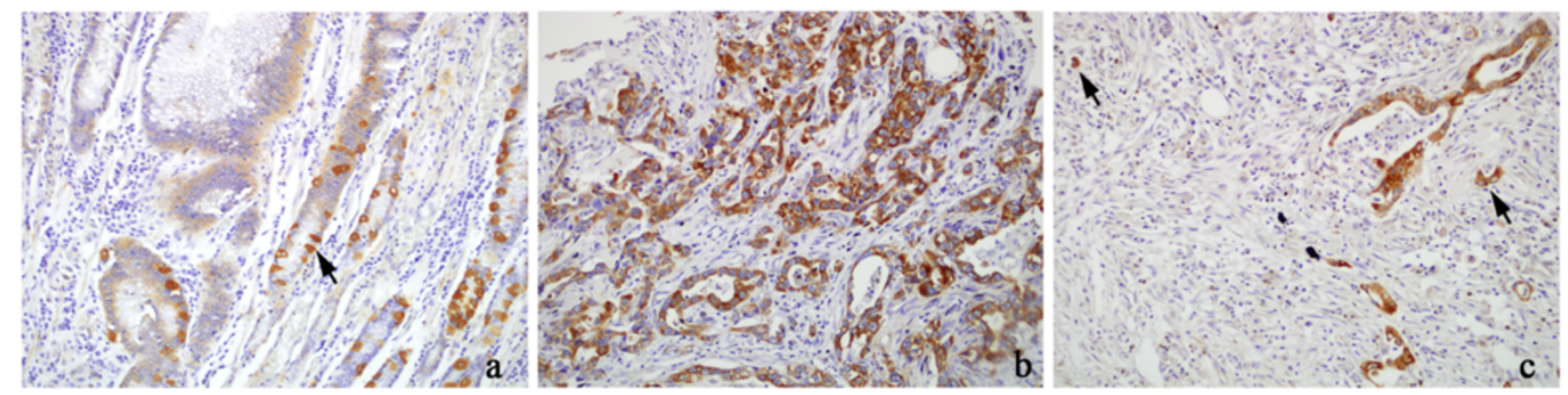

Figure $\mathbf{2}$ Immunoreactivity for Ezrin protein in gastric lesions. Immunohistochemical staining for Ezrin protein in the tissuearray of gastric adenocarcinoma (A). Scattered positive cells (arrows) for Ezrin protein were seen at the cytoplasm of basal reserve cells in gastric normal mucosa (B-a) (200X). The gastric cancer cells showed strongly and diffusely positive staining for Ezrin protein (B-b) (200X). Single scattered cancer cells and invasive cancer loci at the stroma showed intense immunoreactivity for Ezrin protein (arrows) (B-c) (200X).

Human Ezrin gene maps to chromosome 6q25.2-q26 and the total length of mRNA is $3166 \mathrm{bp}$, encoding 585 amino acids. Ezrin has been shown to bind directly to PI3K and influence many signaling pathways that affect cellular functions related to tumorigenesis and metastasis, including MAPK-ERK1/2, PI3K-Akt and Rho pathways. Recently, increasing reports also showed that the critical functions of Ezrin are the regulation of cell shape, motility, adhesion and signal transduction, all of which are important for tumor development and progression [25].

Wang et al. [26] reported that the inhibition of Ezrin expression clearly inhibited the migration and invasion of the human gastric cancer cell line SGC-7901, and increased both cell adhesion and sensitivity to camptothecin-induced apoptosis. Overexpression of Ezrin also promoted cell protrusion, microvillus formation, anchorage-independent growth, motility and invasion in the pancreatic cancer cell line, MiaPaCa-2 [14]. Since then, Ezrin expression has been linked to clinical outcome and prognosis in many cancer types including osteosarcoma, pancreatic carcinoma, hepatocellular carcinoma, and breast carcinoma [14-17].

As a member of ERM protein family, Ezrin functions as a linker protein connecting the actin cytoskeleton (Ezrin C-terminus) to integral plasma membrane proteins (Ezrin N-terminus) [27]. It is proposed that Ezrin exists in a dormant form in which the C-terminal tail binds to and masks the N-terminal FERM domain [28]. Therefore, amino-terminal Ezrin interactions are critical in determining not only the repertoire of proteins Ezrin can interact with but also the corresponding cellular functions that may be positively or negatively affected [27]. This linkage to the cell membrane allows the cells to physically engage and potentially sense the tumor microenvironment [27,28]. Elzagheid et al. [22] reported that Ezrin was predominantly expressed at the apical cell membrane in a polarized fashion in normal colonic epithelium. In contrast, Ezrin expression in the cancer cells was typically cytoplasmic. In the present study, Ezrin protein was found to locate in the cytoplasm and/or 


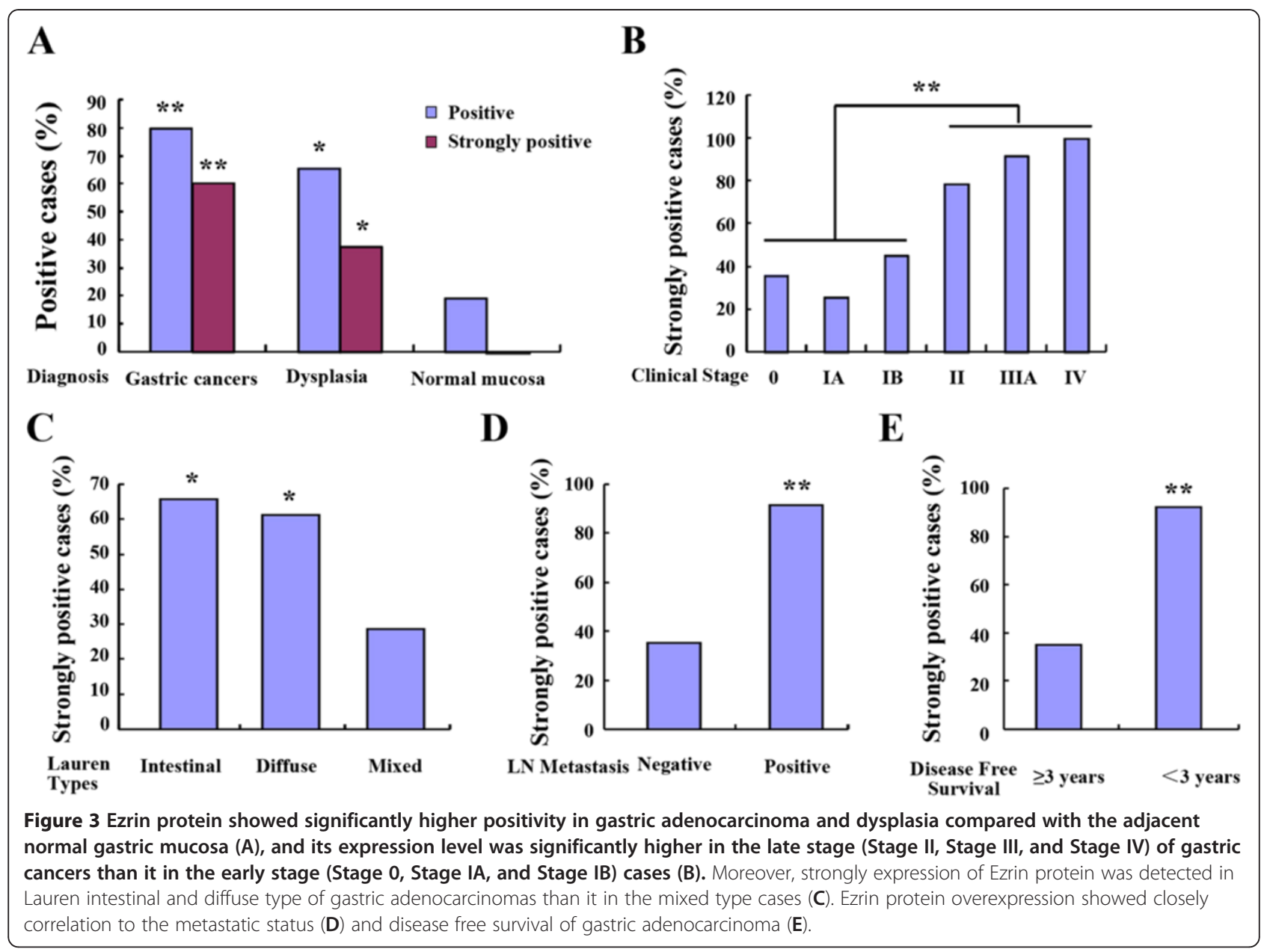

membrane in the migrating gastric cancer cells in vitro, and it mainly concentrated at the protrusion site of MKN-1 gastric cancer cells; however, Ezrin protein located only in the cytoplasm in non-migrating cells in vitro by immunofluorescence staining (Figure 1). By the immunohistochemistry, the diffusely and strongly positive signals for Ezrin protein was detected in the cytoplasm of gastric cancer cells; however, negative or scattered positive cells (mainly basal reserve cells) was observed in the cytoplasm of normal gastric epithelia, indicating that the subcellular distribution of Ezrin was

Table 1 Ezrin protein expression in gastric adenocarcinoma

\begin{tabular}{lccccc}
\hline \multicolumn{1}{c}{ Diagnosis } & $\begin{array}{c}\text { Number } \\
\text { of cases }\end{array}$ & $\begin{array}{l}\text { Positive cases } \\
\end{array}$ & & $\begin{array}{l}\text { Positive } \\
\text { rate (\%) }\end{array}$ & $\begin{array}{l}\text { Strongly } \\
\text { positive } \\
\text { rate (\%) }\end{array}$ \\
\hline Gastric adenocarcinoma & 277 & 565310266 & $79.8 \%^{* *}$ & $60.6 \%^{* *}$ \\
Dysplasia & 32 & 119120 & $65.6 \%^{*}$ & $37.5 \%^{*}$ \\
Normal mucosa & 26 & 21500 & $19.2 \%$ & 0 \\
\hline
\end{tabular}

Compared with normal mucosa ${ }^{*} \mathrm{P}<0.05,{ }^{*} \mathrm{P}<0.01$. Strongly positive: ++ and +++ . predominantly cytoplasmic distribution in nonmigrating cancer or normal cells, but mainly membranous distribution in the migrating cells in vitro. This is consistent with the previous reports in other epithelial human tumors. However, apical localization of Ezrin protein was seen neither in gastric carcinoma nor in normal gastric epithelia by immunohistochemistry. More interestingly, scattered single cancer cells at the stroma frequently showed stronger and most intense immunoreactivity in this study, and similar observations was reported previously in colorectal cancers by Elzagheid et al. [22] and endometrioid carcinomas by Köbel et al. [29] and Yasuoka et al. [30]. These data indicated that Ezrin might be essential for the processes of gastric cancer cells, including the determination of cell shape, polarity and formation of surface structures, motility, and integration of membrane transport with signaling pathways. But the detailed mechanism needs to be explored by the further study.

Recently, it has been shown that Ezrin plays a pivotal role in the progression of gastrointestinal carcinoma [2,18-20,22]. Elzagheid et al. [22] reported that Ezrin 
Table 2 Relationship between Ezrin protein overexpression and clinicopathological features of gastric adenocarcinoma

\begin{tabular}{lll}
\hline Clinical features & $\begin{array}{l}\text { No. of } \\
\text { cases }\end{array}$ & $\begin{array}{l}\text { Strongly } \\
\text { positive } \\
\text { cases (\%) }\end{array}$
\end{tabular}

\begin{tabular}{|c|c|c|c|}
\hline \multicolumn{4}{|l|}{ Age } \\
\hline$<50$ & 96 & $60(62.5 \%)$ & NS \\
\hline $51-69$ & 181 & $92(50.8 \%)$ & \\
\hline$\geq 70$ & 29 & $16(55.2 \%)$ & \\
\hline Gender & & & NS \\
\hline Male & 164 & $102(62.2 \%)$ & \\
\hline Female & 113 & $66(58.4 \%)$ & \\
\hline Lauren Types & & & $<0.05, a$ \\
\hline Intestinal type & 117 & 77 (65.8\%) & \\
\hline Diffuse type & 139 & $85(61.2 \%)$ & \\
\hline Mixed type & 21 & $6(28.6 \%)$ & \\
\hline WHO's Histological Types & & & NS \\
\hline Well-diff. ade. & 85 & $42(49.4 \%)$ & \\
\hline Moderately-diff. ade. & 103 & $54(52.4 \%)$ & \\
\hline Poorly-diff. ade. & 59 & $50(84.7 \%)$ & \\
\hline Undifferentiated ade. & 5 & $3(60.0 \%)$ & \\
\hline Signet ring cell carcinoma & 9 & $5(55.6 \%)$ & \\
\hline Mucinous ade. & 16 & $14(87.5 \%)$ & \\
\hline LN Metastasis & & & $<0.01$ \\
\hline Negative & 151 & $53(35.1 \%)$ & \\
\hline Positive & 126 & $115(91.3 \%)$ & \\
\hline Clinical Stage & & & $<0.05, \boldsymbol{b}$ \\
\hline 0 & 39 & $14(35.9 \%)$ & \\
\hline IA & 47 & $12(25.5 \%)$ & \\
\hline IB & 51 & $23(45.1 \%)$ & \\
\hline$\|$ & 75 & $59(78.7 \%)$ & \\
\hline$\| I I A$ & 59 & $54(91.5 \%)$ & \\
\hline IV & 6 & $6(100 \%)$ & \\
\hline Disease Free Survival & & & $<0.01$ \\
\hline$\geq 3$ years & 152 & $53(34.9 \%)$ & \\
\hline$<3$ years & 125 & $115(92.0 \%)$ & \\
\hline
\end{tabular}

ade.: Adenocarcinoma; diff.: differentiated; NS: not significant.

* Strongly positive: ++ and +++.

a: Intestinal \& Diffuse types vs Mixed type.

b: Stage 0 + Stage IA + Stage IB vs Stage II + Stage IIIA + Stage IV.

may play a role in colorectal cancer progression and that Ezrin expression might provide clinically valuable information in predicting the biological behavior of colorectal cancer. Zhao et al. [19] reported that overexpression of Ezrin promoted gastric cancer cell invasion, whereas inactivating Ezrin function with small interference RNA caused reduced cell invasion, indicating a potential role of Ezrin in regulating the progression to invasive gastric cancer. In the present study, 277 cases of gastric adenocarcinomas, 32 of dysplasia, and 26 of normal gastric mucosa were investigated, and it was found that Ezrin expression was significantly up-regulated in gastric cancers and dysplasia compared with normal gastric mucosa, however no difference was found between gastric cancer and dysplasia, indicating that Ezrin protein overexpression could be used as the early diagnostic marker for gastric cancer and its precancerous disease.

It is well known that TNM staging system according to The American Joint Committee on Cancer (AJCC)/ International Union against Cancer (UICC) produced the most reliable system for predicting the survival of patients. Furthermore lymphatic and vascular invasion were also considered as poor prognostic indicators [31]. Limited reports suggest that Ezrin may be a useful prognostic and survival indicator for gastric cancers. Zhao et al. [19] and Fan et al. [2] demonstrated that Ezrin was required for the invasion of gastric cancer cells. However, Bal et al. [18] reported that no statistically significance was found about the correlation of ezrin overexpression and lymph node metastasis, lymphovascular space invasion, and distant metastasis. Here we found that the strongly positive rate of Ezrin protein expression was significantly higher in metastatic gastric cancer $(91.3 \%)$ than it in non-metastatic cancer cases (35.1\%) $(\mathrm{P}<0.01)$. For the TNM clinical stages, the strongly positive rate of Ezrin was lower in Stage 0 (35.9\%) and stage I (Stage IA: 25.5\%; Stage IB: 45.1\%) compared with Stage II (78.7\%), Stage III (91.5\%) and Stage IV (100\%), the difference was statistically significant $(\mathrm{P}<0.05)$, demonstrating that Ezrin protein overexpression was strongly correlated with the lymph node metastasis and clinical stage of gastric cancers. Additionally, Li et al. [20] reported that for 436 gastric cancer patients with stage I, II or III disease, the 5-year survival rate for those with high Ezrin expression were significantly lower than in patients with low expression. Zhao et al. [19] also reported that the survival rate of patients with Ezrin or c-Met positive gastric cancers were significantly lower than those in patients with Ezrin or c-Met negative tumors $(\mathrm{P}<0.05)$. However, here we also found that the strongly positive rate of Ezrin protein expression was significantly higher in $<3$ years disease free survival cases $(92.0 \%)$ than it in ${ }^{3} 3$ years disease free survival cases $(34.9 \%)(\mathrm{P}<0.01)$. All above data strongly indicated that Ezrin could be regarded as a potential prognostic factor in gastric cancers.

Moreover, Lam et al. [32] reported that among 150 gastric cancer cases, 33 (22.0\%) cases showed low Ezrin expression, $92(61.3 \%)$ cases showed moderate Ezrin expression and 25 (16.7\%) cases showed high Ezrin expression. Ezrin expression was associated with Lauren type and differentiation but not correlated with the patients' 
age and gender. However, $\mathrm{Li}$ et al. [20] reported that Ezrin positive expression is correlated with age, tumor size and location, grading and poor prognosis. In the present study, higher strongly expression rate of Ezrin protein was detected in intestinal type (65.8\%) and diffuse type (61.2\%) of gastric cancer than that in the mixed type (28.6\%) cases. But Ezrin protein expression level was not correlated with the patient age, gender, WHO's histological type status of gastric carcinomas $(\mathrm{P}>0.05)$. This is consistent with Lam's report, but it needs the further study to verify.

All above data point to the importance of Ezrin not only as a useful marker of early diagnosis and prognosis but also as a potential therapeutic target in gastric adenocarcinoma. The high frequency of Ezrin expression suggests a central role in gastric cancer biology, though the further study needs to be investigated for exploring the mechanism in detail. In summary, the detection of Ezrin protein expression could be used as an early diagnostic marker of gastric cancer and its precancerous disease, and Ezrin overexpression could predict the poor prognosis of gastric adenocarcinoma, suggesting that Ezrin might be a potential molecular target for gastric adenocarcinoma therapy.

\section{Competing interests}

Authors declare no conflict of interests.

\section{Author's contributions}

$\mathrm{J}$ and JT participated in study conception, design, case selection and immunohistochemical staining. QM and PY carried out immunofluorescence staining and data collection. PY and LZ performed data analysis and writing the manuscript. All the authors read and approved the final manuscript.

\section{Acknowledgements}

This work was funded by National Natural Science Foundation of China (NSFC, no.30960120 \& no.31060158), Project from the Science and Technology Department of Jilin Province of China (no.200950204), Project from the Education Department of Jilin Province of China (no.2009-24), and The Basic Scientific Research Fund from Jilin University.

The authors would like to thank Jie Zhang and Shusen Liu, Department of Pathology, Yanbian University Medical College, for help with the confocal microscopic observation and tissue section.

\section{Author details}

'Department of Pathology, Yanbian University Medical College, Yanji-City 133002, Jilin-Prov., P.R. China. ${ }^{2}$ Cancer Research Center, Yanbian University, Yanji-City 133002, Jilin-Prov., P.R. China. ${ }^{3}$ Department of Pathophysiology, Yanbian University Medical College, Yanji-City 133002Jilin-Prov., P.R. China ${ }^{4}$ Department of Internal Medicine, Yanbian University Affiliated Hospital, Yanji-City 133000Jilin-Prov., P.R. China.

Received: 16 July 2012 Accepted: 25 September 2012 Published: 5 October 2012

\section{References}

1. Youn HG, An JY, Choi MG, Noh JH, Sohn TS, Kim S: Recurrence after curative resection of early gastric cancer. Ann Surg Oncol 2010, 17:448-454.

2. Fan $L L$, Chen DF, Lan $C H$, Liu KY, Fang DC: Knockdown of ezrin via RNA interference suppresses Helicobacter pylori-enhanced invasion of gastric cancer cells. Cancer Biol Ther 2011, 11:746-752.

3. Elzagheid A, Algars A, Bendardaf R, Lamlum H, Ristamaki R, Collan Y, Syrjanen $\mathrm{K}$, Pyrhonen S: E-cadherin expression pattern in primary colorectal carcinomas and their metastases reflects disease outcome. World J Gastroenterol 2006, 12:4304-4309.

4. McClatchey Al: Merlin and ERM proteins: unappreciated roles in cancer development. Nat Rev Cancer 2003, 3:877-883.

5. Hunter KW: Ezrin, a key component in tumor metastasis. Trends Mol Med 2004, 10:201-204.

6. Louvet-Vallee S: ERM proteins:from cellular architecture to cell signaling Biol Cell 2000, 92:305-316.

7. Yu Y, Khan J, Khanna C, Helman L, Meltzer PS, Merlino G: Expression profiling identifies the cytoskeletal organizer ezrin and the developmental homeoprotein Six-1 as key metastatic egulators. Nat Med 2004, 10:175-181.

8. Mak H, Naba A, Varma S, Schick C, Day A, Sengupta SK, Arpin M, Elliott BE: Ezrin phosphorylation on tyrosine 477 regulates invasion and metastasis of breast cancer cells. BMC Cancer 2012, 12:82.

9. Gould KL, Bretscher A, Esch FS, Hunter T: cDNA cloning and sequencing of the protein-tyrosine kinase substrate, ezrin, reveals homology to band 4.1. EMBO J 1989, 8:4133-4142.

10. Bretscher A, Edwards K, Fehon RG: ERM proteins and merlin: integrators at the cell cortex. Nat Rev Mol Cell Biol 2002, 3:586-599.

11. Wu B, Li J, Huang D, Wang W, Chen Y, Liao Y, Tang X, Xie H, Tang F: Baicalein mediates inhibition of migration and invasiveness of skin carcinoma through Ezrin in A431 cells. BMC Cancer 2011, 11:527.

12. Mäkitie T, Carpén $O$, Vaheri A, Kivelä T: Ezrin as a prognostic indicator and its relationship to tumor characteristics in uveal malignant melanoma. Invest Ophthalmol Vis Sci 2001, 42:2442-2449.

13. Weng WH, Ahlén J, Aström K, Lui WO, Larsson C: Prognostic impact of immunohistochemical expression of ezrin in highly malignant soft tissue sarcomas. Clin Cancer Res 2005, 11:6198-6204.

14. Meng Y, Lu Z, Yu S, Zhang Q, Ma Y, Chen J: Ezrin promotes invasion and metastasis of pancreatic cancer cells. J Trans/ Med 2010, 8:61.

15. Chen Y, Wang D, Guo Z, Zhao J, Wu B, Deng H, Zhou T, Xiang H, Gao F, Yu X, Liao J, Ward T, Xia P, Emenari C, Ding X, Thompson W, Ma K, Zhu J, Aikhionbare F, Dou K, Cheng SY, Yao X: Rho Kinase Phosphorylation Promotes Ezrin-Mediated Metastasis in Hepatocellular Carcinoma. Cancer Res 2011, 71:1721-1729.

16. Zheng S, Huang J, Zhou K, Zhang C, Xiang Q, Tan Z, Wang T, Fu X: 17Estradiol enhances breast cancer cell motility and invasion via extranuclear activation of actin-binding protein Ezrin. PLoS One 2011, 6:e22439.

17. Zhu J, Feng Y, Ke Z, Yang Z, Zhou J, Huang X, Wang L: Down-Regulation of miR-183 Promotes Migration and Invasion of Osteosarcoma by Targeting Ezrin. Am J Pathol 2012, 180(6):2440-2451.

18. Bal N, Yildirim S, Nursal TZ, Bolat F, Kayaselcuk F: Association of ezrin expression in intestinal and diffuse gastric carcinoma with clinicopathological parameters and tumor type. World J Gastroenterol 2007, 13:3726-3729.

19. Zhao J, Zhang $X$, Xin Y: Up-regulated expression of Ezrin and c-Met proteins are related to the metastasis and prognosis of gastric carcinomas. Histol Histopathol 2011, 26:1111-1120.

20. Li L, Wang YY, Zhao ZS, Ma J: Ezrin is associated with gastric cancer progression and prognosis. Pathol Oncol Res 2011, 17:909-915.

21. AJCC: AJCC Cancer Staging Manual. 6th edition. New York: Springer Verlag; 2002

22. Elzagheid A, Korkeila E, Bendardaf R, Buhmeida A, Heikkilä S, Vaheri A, Syrjänen K, Pyrhönen S, Carpén O: Intense cytoplasmic ezrin immunoreactivity predicts poor survival in colorectal cancer. Hum Pathol 2008, 39:1737-1743.

23. Demirag GG, Sullu Y, Gurgenyatagi D, Okummus NO, Yucel I: Expression of Plakophilins (PKP1, PKP22, and PKP3) in gastric cancers. Diagn Pathol 2011, 6:1-5.

24. Brenner $\mathrm{H}$, Rothenbacher D, Arndt: Epidemiology of stomach cancer. Methods Mol Biol 2009, 472:467-477.

25. Fais S: A role for ezrin in a neglected metastatic tumor function. Trends Mol Med 2004, 10:249-250.

26. Wang HJ, Zhu JS, Zhang Q, Guo H, Dai YH, Xiong XP: RNAi-mediated silencing of ezrin gene reverses malignant behavior of human gastric cancer cell line SGC-7901. J Dig Dis 2009, 10:258-264.

27. Briggs JW, Ren L, Nguyen R, Chakrabarti, Cassavaugh J, Rahim S, Bulut G, Zhou M, Veenstra TD, Chen Q, Wei JS, Khan J, Uren A, Khanna C: The ezrin metastatic phenotype is associated with the initiation of protein translation. Neoplasia 2012, 14:297-310. 
28. Berryman M, Franck Z, Kawai A: Ezrin is concentrated in the apical microvilli of a wide variety of epithelial cells whereas moesin is found primarily in endothelial cells. J Cell Sci 1993, 105:1025-1043.

29. Köbel M, Langhammer T, Hüttelmaier S, Schmitt WD, Kriese K, Dittmer J, Strauss HG, Thomssen C, Hauptmann S: Ezrin expression is related to poor prognosis in FIGO stage I endometrioid carcinomas. Mod Pathol 2006 19:581-587

30. Yasuoka H, Tsujimoto M, Inagaki M, Kodama R, Tsuji H, Iwahashi Y, Mabuchi Y, Ino K, Sanke T, Nakamura Y: Clinicopathological significance of podocalyxin and phosphorylated ezrin in uterine endometrioid adenocarcinoma. J Clin Pathol 2012, 65(5):399-402.

31. Catalano V, Labianca R, Beretta GD, Gatta G, de Braoud F, Van Cusem E: Gastric cancer. Crit Rev Oncol Hematol. 2009, 71(2):127-164

32. Lam EK, Wang X, Shin VY, Zhang S, Morrison H, Sun J, Ng EK, Yu J, Jin H: A microRNA contribution to aberrant Ras activation in gastric cancer. Am J Transl Res 2011, 3:209-218.

doi:10.1186/1746-1596-7-135

Cite this article as: Jin et al.: Ezrin overexpression predicts the poor prognosis of gastric adenocarcinoma. Diagnostic Pathology 2012 7:135.

\section{Submit your next manuscript to BioMed Central and take full advantage of:}

- Convenient online submission

- Thorough peer review

- No space constraints or color figure charges

- Immediate publication on acceptance

- Inclusion in PubMed, CAS, Scopus and Google Scholar

- Research which is freely available for redistribution 